\title{
Study of reclaimed water system in downtown Los Angeles based on system dynamics theory
}

\author{
Gang Wang ${ }^{1,}$ Qingbo Wen $^{1}$, Liming $H U^{1 *}$, and Jay $N$ MEEGODA ${ }^{1,2}$ \\ ${ }^{1}$ State Key Laboratory of Hydro-Science and Engineering, Department of Hydraulic Engineering, \\ Tsinghua University, Beijing, 100084, CHINA \\ ${ }^{2}$ Department of Civil and Environmental Engineering, New Jersey Institute of Technology, Newark, \\ New Jersey, USA.
}

\begin{abstract}
The shortage of water resources has seriously restricted the development of cities. Unconventional water resources is of great significance for sustainable development. As a city lack of water, Los Angeles plans to develop reclaimed water as an important component of urban water supply under the conditions of drought and over exploitation of groundwater. In order to provide a basis for urban reclaimed water construction planning, this paper developed a system dynamic model to provide scientific suggestions for the planning of reclaimed water. According to the analysis of Los Angeles water system, the model divides the system into reclaimed water system, urban water consumption system, urban water supply system and water supply cost system. The degree of water shortage, urban water supply, water supply cost, and reclaimed water production were chosen as the model index for the requirement of plan design. The historical data was employed to verify the model, indicating that the model is reliable. Then the plans under different rates of growth of reclaimed water were designed. According to the comprehensive analysis of the model index, the second plan was considered to be the optimal one: increase the local water supply in Los Angeles to 50 percent of the total by 2035 and reduce purchases by 50 percent. Finally, Reclaimed water accounts for $30 \%$ of the city's water supply, meanwhile, water supply costs decline $10 \%$.
\end{abstract}

Keywords: unconventional water resources (UWR); reclaimed water; water shortage; system dynamics

\section{Introduction}

In recent years, with the increase of urban population and the development of social economy, water resource shortage has become a non-negligible factor restricting social development. Developing new water resources and optimizing water resources management are of great significance for solving the current water resources crisis and sustainable development of

\footnotetext{
* Corresponding author: gehu@tsinghua.edu.cn (L. Hu).
} 
cities. As a very important water supply, unconventional water resources (UWR) including the reclaimed water have great potential. The maximum potential for reuse of reclaimed water is thought to be close to $60 \%$ of the city's water supply [1]. As a kind of renewable water resource, recycled water has significant advantages: reliable source, stable water supply, reduction of environmental pollution, consistent with the concept of sustainable development [2]. However, as a new water resource, the planning of reclaimed water needs to be studied. This paper aims to take Los Angeles as a case to provide an example analysis for the planning of reclaimed water.

Los Angeles is the second largest city in the United States. In 2015, the urban population was about 3.97 million and the GDP was about $\$ 750$ billion. Los Angeles has a temperate Mediterranean climate. The climate is dry throughout the year with low rainfall of about 362 $\mathrm{mm}$ and evaporation of $1155 \mathrm{~mm}$. As a mega city with a large population and developed economy, Los Angeles has a great demand for water resources. But the city is so short of water because of climate conditions that the city plans to develop recycled water as a new source of water in the next 20 years to keep the city's water supply safe. To sum up, there is a need to develop reclaimed water in Los Angeles, which requires research on reclaimed water planning. At the same time, Los Angeles is not a special case, many cities such as Beijing and Tianjin are short of water. So the analysis of Los Angeles is helpful for the study of renewable water planning in mega cities.

The development and utilization of reclaimed water need scientific planning method. System dynamics (SD) is an analytical method for studying the behavior of a system. SD, proposed by Jay W. Forrester in 1956, aims at solving the simulating problems of large-scale systems by integrating systems theory, cybernetics, information theory and computer technology. SD can be used to study the interaction of factors within the system and the behavior and trend of the system in the future [3]. In recent years, SD model provides an analytical tool for solving complex system problems in social, economic and ecological fields, especially in the complex social system simulation, water resources protection [4-6], enterprise strategy formulation and other aspects.

Taking Los Angeles as a case, this paper develops a SD model of urban reclaimed water system, aiming to provide the prediction results of urban sewage treatment plans, and give the planning, design and optimization methods of reclaimed water.

\section{Methodology}

SD model has been widely applied in water resources management. For example, from the perspective of sustainable utilization of water resources, X.H. Zhang et al(2007) applied Sd model to water resources management in Tianjin[7]. Xi Xia, et al(2013) used the sd model to predict the future water demand of Singapore[8]; From the perspective of increasing the utilization of reclaimed water, Z, X et al(2002) takes the Yellow River as a case[9]. J. m. Fernandez (2003) carried out the study of SD model in Spain [10]. This paper will study the future water use and utilization of reclaimed water in Los Angeles, and provide a basis for the planning of reclaimed water. When applying system dynamics to solve problems, the causal relationship diagram of the system should be established firstly according to the structure of system variables, and then the stock flow diagram should be established on the basis of causal relationship according to the attributes of variables and their mutual influence. 
Finally dynamo language was used to program the graphic software to obtain the difference mathematical model of the system [11].

The procedures for applying SD model to water resources planning are as follows [12]:

1 Defining the system boundary: Identify the boundary of the problem, including determining the time span of the problem and time interval. Identify the key variables of the system, as well as the historical behavior of the variables. The main purpose of this step is to determine the boundary of the system and its variables.

2 Determining the system structure: Determine the causal chain within the system. By analyzing the relationship between variables, the relationship between system variables is determined. The main result of this step is to make the causal loop diagram of the system.

3. Model building: Determine the type of variables, that is, determine the leveling variable and rate variable in the feedback loop. The leveling variable represents the state of the system at a certain time, while the rate variable is the description of system changes. Finally, the functional relationship between variables is determined. The main purpose of this step is to establish the stock flow diagram.

4 Simulation: Simulation test is conducted to judge whether the model can meet the previous data. After the model passes the simulation test, the model can be simulated to predict the trend of variables in the future. The simulation of several plans can also be compared to provide a basis for the planning and design of the system.

\section{Case study}

As a water-short metropolis, Los Angeles has severe water shortage restrictions, so the need to develop new water resources is very strong. This chapter will take Los Angeles as a case to establish an SD model to explore the future development of reclaimed water in Los Angeles. The feasibility of the model is confirmed through the historical simulation test. The model was used to predict the urban water supply, reclaimed water production and water supply cost of Los Angeles in the next 20 years under different plans, and the optimal plan was determined. It provides a basis for the planning of reclaimed water and a reference for the application of reclaimed water in other cities like Los Angles.

\subsection{Research area}

Los Angeles, located in southwestern California, is the second largest city in the United States. Los Angeles covers an area of 1215 square kilometers, and its central coordinates are $34^{\circ} 03$ 'north latitude and $118^{\circ} 15^{\prime}$ west longitude. The city has a population of about 3.976 million (2016). In 2016, the gross regional product of Los Angeles was $\$ 753.1$ billion. Los Angeles has a temperate Mediterranean climate throughout the year. Generally dry with little rain all year round, but a little more in winter. The annual precipitation is about $378 \mathrm{~mm}$, mainly in winter. The Los Angeles river, a major seasonal river flowing through the city, is about 82 $\mathrm{km}$ long. 


\subsection{Model construction}

The boundary of the model is the urban area of the city of Los Angeles, including the four boroughs within the water supply area of the city of Los Angeles water authority. According to the research purpose, the model divides the system into reclaimed water system, urban water consumption system, urban water supply system and water supply cost system.

The reclaimed water system follows the main line from sewage volume to secondary treatment volume, and then to reclaimed water volume. In this model, the demand for reclaimed water refers to the portion of urban water that can be replaced by reclaimed water under current technical conditions. The water consumption was divided into residential, industrial, commercial, municipal and other water consumption in Los Angeles. The water supply for Los Angeles includes the Los Angeles aqueduct, groundwater, California water project and recycled water. As a result of the drought of the past 5 years, the average share of water supply has changed considerably.

The supply cost of reclaimed water is described separately in the reclaimed water subsystem. The cost of ground water mainly attributes to personnel operation, transportation pipeline, system operation, electricity and depreciation of fixed facilities. The cost of the Los Angeles aqueduct is mainly composed of the operation cost of the infrastructure and the depreciation cost of the equipment. As the fixed cost of the whole system is higher, generally speaking, the larger the water supply, the lower is the unit cost. The price of water for the California water project depends largely on the quality of the water purchased.

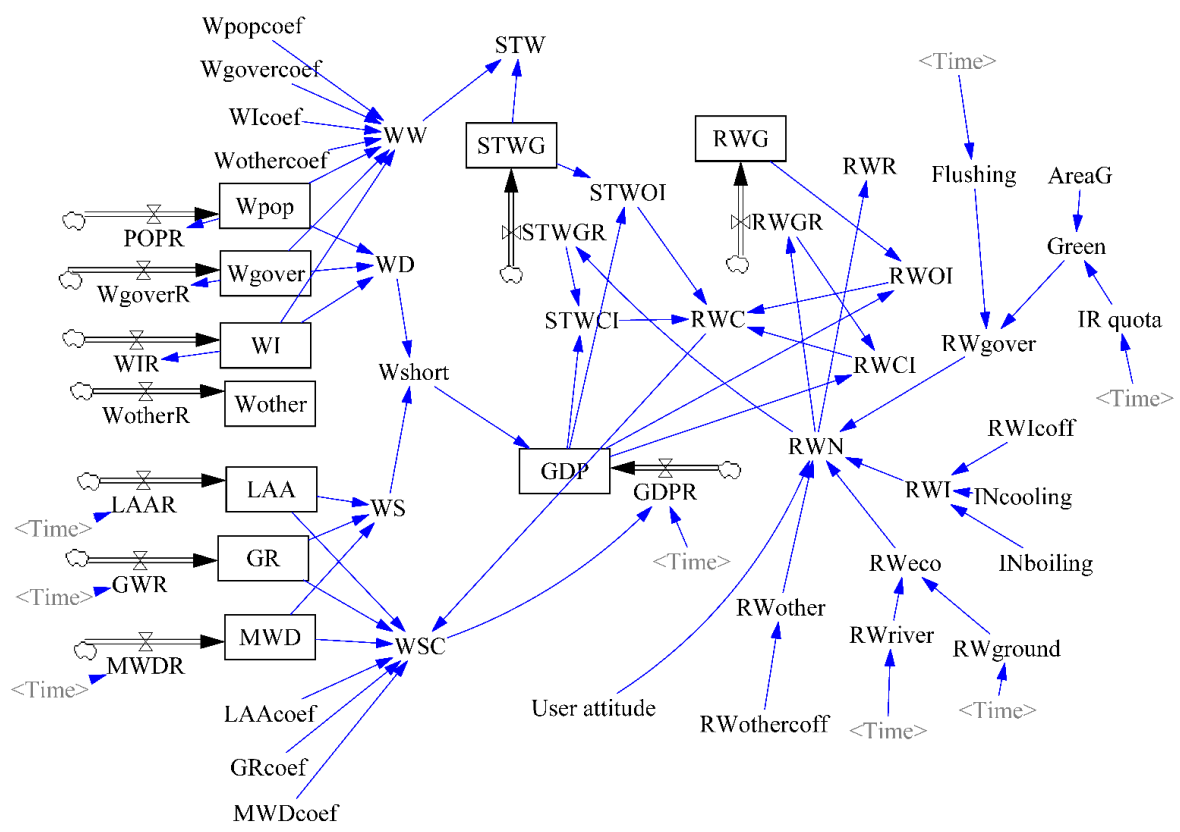

Fig. 1. Flow diagram for LA reclaimed water system 


\subsection{Model test}

Considering that the initial year of model planning and design is 2015, the year of inspection should not be too long ago, otherwise the effect of inspection will be poor. The climate conditions and economic development of the city were integrated to avoid the impact of the financial crisis in 2008. The period from 2010 to 2015 was selected as the historical test time of the model.

Table 1 Model test results

\begin{tabular}{clllllll}
\hline Index & & 2010 & 2011 & 2012 & 2013 & 2014 & 2015 \\
\hline \multirow{2}{*}{ population(million) } & Actual value & 3.796 & 3.823 & 3.849 & 3.876 & 3.903 & 3.931 \\
& predict valve & 3.796 & 3.827 & 3.859 & 3.892 & 3.923 & 3.953 \\
& error & 0 & $0.10 \%$ & $0.26 \%$ & $0.41 \%$ & $0.51 \%$ & $0.56 \%$ \\
\hline \multirow{2}{*}{ GDP(billion dollars) } & actual value & 683.1 & 697.5 & 712.2 & 727.3 & 742.6 & 758.3 \\
& predict valve & 683.1 & 697.2 & 718.1 & 736.1 & 751.6 & 760.3 \\
& error & 0 & $0.04 \%$ & $0.83 \%$ & $1.21 \%$ & $1.21 \%$ & $0.26 \%$ \\
\hline \multirow{2}{*}{ water supply(billion Cubic meter) } & predict valve & 0.655 & 0.671 & 0.696 & 0.727 & 0.713 & 0.701 \\
& error & 0 & $0.45 \%$ & $2.20 \%$ & $4.60 \%$ & $0.56 \%$ & $3.04 \%$ \\
\hline
\end{tabular}

From the above error degree, it can be seen that the error of population and GDP is less than 0.01, and considering the drought in Los Angeles in 2014 and 2015, the urban water consumption forecast shows a deviation of $3 \%$. In conclusion, the test result of urban reclaimed water is good and the model passes the test.

\subsection{Model planning}

The model runs for a period of 20 years with 2015 chosen as base year. The design of the simulation plan mainly considers the growth rate of reclaimed water in the city. By considering the future prediction, optimistic estimation and conservative estimation of urban development, five simulation plans for comparative analysis were designed. Because of the influence degree of urban decision variables, urban water consumption, renewable water supply, total urban water supply cost and unit water supply cost were selected as the output indicators. Through the comprehensive comparison of these indicators, the final optimization plan is obtained.

Five plans are considered, one of which is the base case assuming that the existing parameters will be kept in the future. Plan 2 is optimistic. Considering that California water project is an emergency water source with higher water supply and higher cost among urban water sources, the city planning decides to increase the proportion of LAA to $50 \%$ by 2035 and reduce the water supply of MWD to 50\% in the next decade. After model debugging, the growth rate of reclaimed water is determined to be $2.5 \%$, and the proportion of reclaimed water and groundwater can reach $50 \%$ by 2035 . 
Plan 3 is a conservative plan. At present, the supply of reclaimed water is still determined by demand, so the future growth rate of reclaimed water is determined according to the city's current intended demand for reclaimed water. Considering that 2015 is a dry year, the water supply of California's water projects is higher than the average level, which decides to reduce the water supply of California's water projects to $50 \%$ by 2035 . Plan 4 was finalized with a growth rate of $1.5 \%$ and Plan 5 with a growth rate of $1 \%$.

Table 2. Major indices on based year (2015)

\begin{tabular}{lll}
\hline variables & value & unit \\
\hline population & 3.97 & million \\
ground water & 83.92 & million cubic meter \\
MWD & 398.64 & million cubic meter \\
LAA & 202.81 & million cubic meter \\
recycled water & 10.28 & million cubic meter \\
government & 50.44 & million cubic meter \\
commercial & 123.21 & million cubic meter \\
industry & 21.78 & million cubic meter \\
other & 39.54 & million cubic meter \\
GDP & 760.3 & billion dollars \\
\hline
\end{tabular}

As shown in Fig. 2, the water supply of Plan 1 is the largest. By 2035, it will exceed 880 million $\mathrm{m}^{3}$, with the highest reliability. The difference between other plans is not significant. Plan 2 effectively replaces the California water project with groundwater and recycled water. Although the city's water supply decreased in the first decade due to reduced demand for California water projects, the final supply (by 2035) will exceed 750 million m. As for Plan 3 , the overall water supply of the city decreased with the reduction of California water resources project, but the water supply increased slightly from 2021 to 2026 due to the increase of reclaimed water. The urban water supply of Plan 4 and Plan 5 decreases, illustrating that the retrieval and utilization of reclaimed water level is still low and there remains great potential in the usage of reclaimed water.

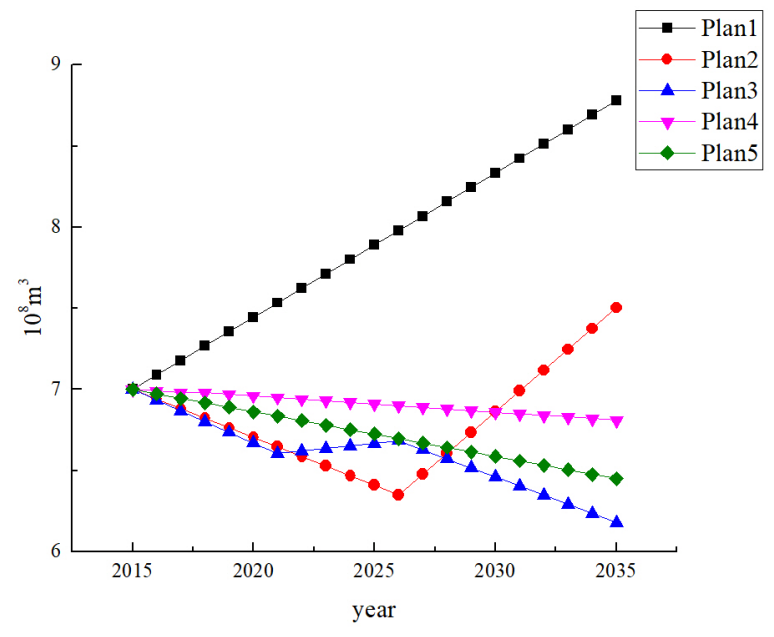


Fig. 2. Urban water supply

Since the recycled water has the characteristics of low cost and stable water source, the larger the recycled water is, the lower the water supply cost of the city will be, and the higher the water supply reliability of the city will be. As can be seen from the figure above, the recycling consumption of plan 2 is the largest. By 2035, the consumption for the reclaimed water is 221.58 million $\mathrm{m}^{3}$, accounting for $30 \%$ of the city's water supply.

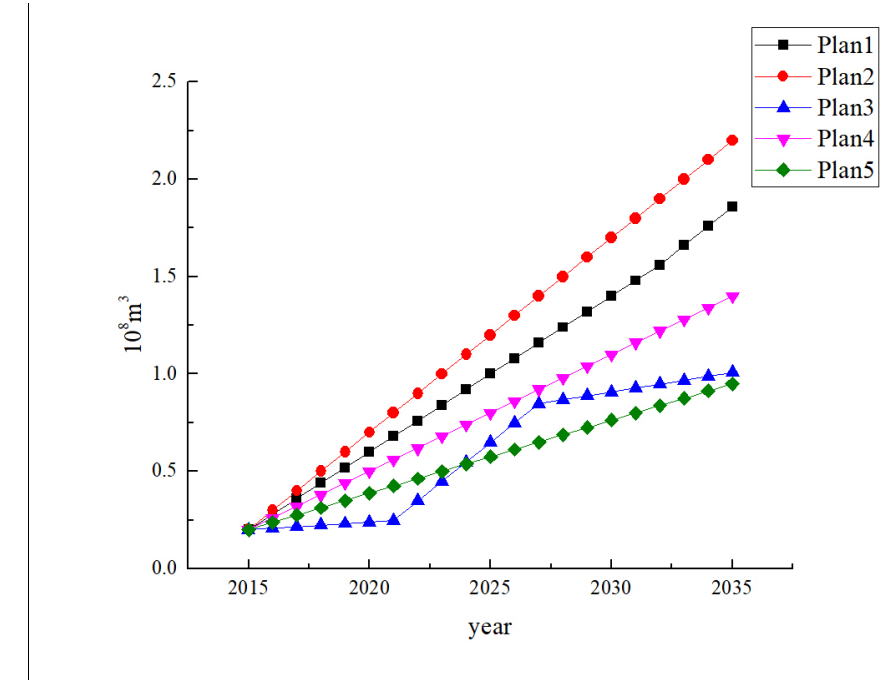

Fig. 3. Reclaimed water production

In terms of the cost per unit of water supply, the plans are similar, with the lowest being $\$ 1.31 / \mathrm{m}^{3}$ in Plan 2. In terms of urban water supply cost, plan 1 has the highest total water supply cost due to the large water supply, exceeding 1.2 billion us dollars and $10 \%$ of the average of other plans. The total water supply cost of other plans shows a trend of decline on the whole. 


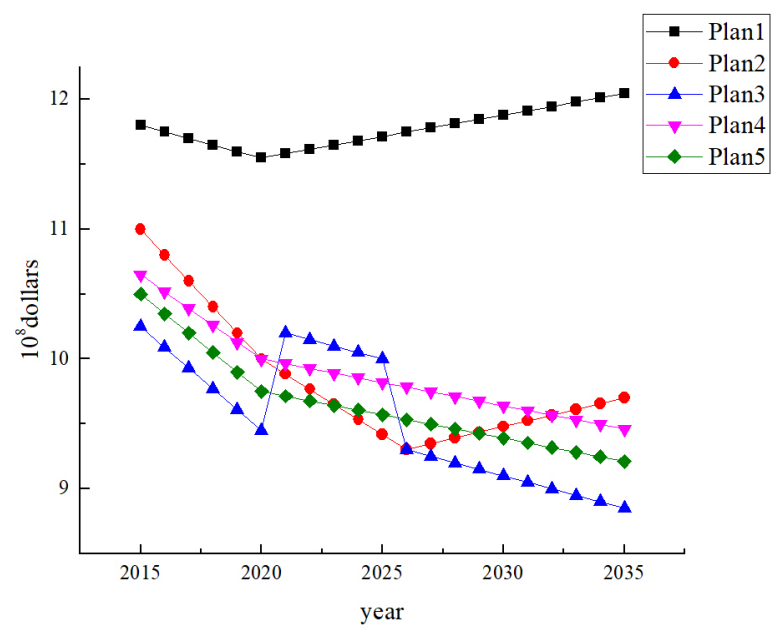

Fig. 4. Total cost of urban water supply

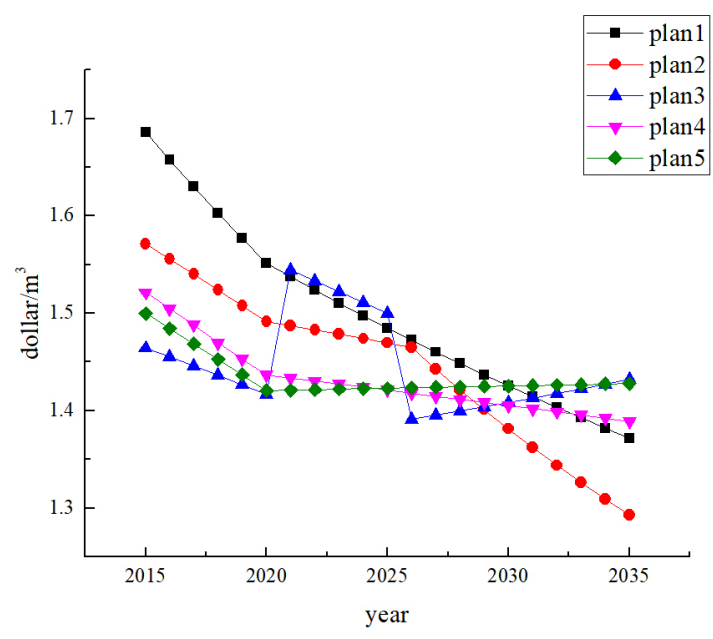

Fig. 5. Urban unit water supply cost

From the perspective of the degree of water shortage, the degree of water shortage is less than 0.1 , so the small impact can be ignored. The degree of water shortage affects the economic development of the city, and the difference in GDP value of Plan 1-5 can be ignored, so it can be considered that all Plans meet the requirements of economic development. From the perspective of urban water supply, plan 1 has the largest water supply and the highest reliability. There is little difference between other plans. The high water supply in Plan 1 resulted in a high total cost, exceeding $\$ 1.2$ billion, $10 \%$ higher than the average of other options. The recycled water consumption can reduce the cost and increase the reliability of water supply. The lowest unit water supply cost is $\$ 1.31 / \mathrm{m}$ of Plan 2. Plan 2 is considered to be the optimal solution because it has the largest recycled water consumption, the lowest unit cost 


\section{Conclusion}

With the development of urbanization and industrialization, water resource shortage has restricted sustainable urban development. As a kind of unconventional water resources, the reclaimed water has great potential in urban water supply. Los Angeles, a water-starved metropolis, plans to increase its investment on reclaimed water over the next two decades to solve water shortages. In this paper, the SD model for Los Angeles reclaimed water is developed, and the interaction between subsystems is simulated dynamically from 2015 to 2035. After verifying the reliability of the model, five plans are designed and simulated. By comparing the output data of the plans, the optimal plan is obtained, and the final result can provide a basis for the subsequent reclaimed water planning.

According to results, the development of reclaimed water has the advantages of great potential and low cost. The second plan was considered to be the optimal one: increase the local water supply in Los Angeles to 50 percent of the total by 2035 and reduce purchases by 50 percent. Finally, Reclaimed water accounts for $30 \%$ of the city's water supply, meanwhile, water supply costs decline $10 \%$. The whole process shows that the dynamic simulation method based on SD model can provide a basis for the rational decision-making of urban planning.

In this paper, the SD is used to build the recycled water system model of Los Angeles, which proves the potential of recycled water as water supply. Through comparison, the optimized plan of reclaimed water is obtained, which can provide a basis for the planning and design of reclaimed water. Finally, the method can provide a reference for the planning and design of reclaimed water in other cities.

This research is funded by National Key R\&D Program of China (Project No. 2017YFC0403501).

\section{References}

1. D. Christova-Boal, R E Eden, S McFarlane. Desalination, 106(1-3): 391-397(1996).

2. J Crook, D K Ammerman, D A Okun, et al. Guidelines for water reuse.(1992).

3. JW Forrester. Urban dynamics. (Cambridge, MIT Press, 1969)

4. I Winz, G Brierley, S Trowsdale. Water Resour. Manag, 23(7):1301-1323.(2009)

5. X Zhang, H Feng, X Mao, et al. International Conference on IEEE(2009).

6. S P Simonovic.J. Environ. Manage., 66(3): 249-267.(2002)

7. X H Zhang, H W Zhang, B Chen, et al. Commun. Nonlinear Sci. Numer. Simul. 13(10): 2328-2336.(2008)

8. X Xi, K L Poh. Procedia Computer Science, , 16: 157-166.(2013)

9. Z X Xu, K Takeuchi, H Ishidaira, et al. Water Resour. Manag. 16(3): 239-261.(2002)

10. J M Fernández, M A E Selma. Syst. Dyn. Rev. , 20(2): 117-137.(2004)

11. R Rehan, M A Knight, C T Haas, et al. Water Res., 45(16): 4737-4750.(2011)

12. L H Feng, X C Zhang, G Y Luo. Math. Comput. Simul., 79(3): 269-278.(2008) 